\title{
The British National Diet and Nutrition Survey of people aged 65 years or over: protocol and feasibility study
}

\author{
BY J. M. HUGHES, G. SMITHERS AND C. GAY
}

Ministry of Agriculture, Fisheries and Food, Nobel House, 17 Smith Square, London SWIP 3JR

AND P. C. CLARKE

Department of Health, Skipton House, 80 London Road, London SEl $6 \mathrm{LW}$

AND P. SMITH AND C. LOWE

Social and Community Planning Research, 35 Northampton Square, London ECIV OAX

\author{
AND A. PRENTICE, C. BATES AND M. WHITELAW \\ MRC Dunn Nutrition Unit, Milton Road, Cambridge CB4 $1 X J$
}

AND S. BINGHAM

MRC Dunn Clinical Nutrition Centre, Hills Road, Cambridge CB2 2DH

The present paper reports the protocol and some outcomes of a feasibility study of the British National Diet and Nutrition Survey (NDNS) of people aged 65 years or over. The feasibility study was carried out in February and March 1994 in order to develop and test all components of the protocol for the main survey. The fieldwork for the main survey takes place over 12 months and began in October 1994.

The NDNS of people aged 65 years or over is one component of a survey programme which has been established by the Ministry of Agriculture, Fisheries and Food (MAFF) and the Department of Health. It follows the successful completion and evaluation of a study of the diet and nutritional status of British adults (aged 16-64 years) in 1986-7 (Gregory et al. 1990).

The core NDNS programme is split into four separate cross-sectional surveys, conducted at approximately two-yearly intervals. It is intended that each survey will examine a nationally-representative sample drawn from one of four different population agegroups: children aged 1.5-4.5 years, schoolchildren aged $4-18$ years, adults aged 16-64 years, adults aged 65 years or over.

The main objectives of the NDNS programme are to:

(1) provide detailed quantitative information on the food and nutrient intake, sources of nutrients and the nutritional status of individuals as a basis for Government policy;

(2) establish normal ranges for nutrient intakes and nutritional status markers;

(3) monitor the diet of the population to establish the extent to which it is adequately nutritious and varied;

(4) monitor progress towards dietary targets e.g. dietary reference values;

(5) determine possible relationships between morbidity, cause of death and diet;

(6) estimate the intakes of food chemicals including pesticides, additives, natural toxicants and contaminants for risk assessment.

THE NATIONAL DIET AND NUTRITION SURVEY PROGRAMME TO DATE

The fieldwork for the survey of children aged 1.5-4.5 years, which included 1700 children, was conducted from July 1992 to June 1993. A report has been prepared and 
was published in March (Gregory et al. 1995). The data for each survey will be deposited at the Economic and Social Research Council Data Archive at the University of Essex, to enable other researchers to have access.

It was decided to carry out next the survey of adults aged 65 years or over (before school-aged children) because the last national survey of diet and nutrition of this population was over 20 years ago (Department of Health and Social Security, 1979), whereas a survey of schoolchildren has been carried out more recently in 1982-3 (Department of Health, 1989). The proportion of elderly people in Western societies is increasing rapidly and nutrition is a major factor in maintaining good health at a time when chronic diseases are a burden to the individual. The Committee on Medical Aspects of Food Policy (COMA) Report: The Nutrition of Elderly People (Department of Health, 1992) highlighted the need for up-to-date information on the dietary requirements of this age-group.

Schoolchildren will be the next group to be surveyed after adults 65 years and over, then back to adults up to 64 years. The cycle of the NDNS programme will take about 10 years to complete. There is some scope to survey special groups, e.g. vegetarians, pregnant women, in addition to this core programme.

\section{COMPONENTS OF THE NATIONAL DIET AND NUTRITION SURVEY}

In order to achieve the objectives of the NDNS programme the following components need to be included in the survey:

(1) an interview to collect classificatory information;

(2) dietary intake record;

(3) bowel movement record;

(4) anthropometric and physical measurements;

(5) blood pressure;

(6) fasting blood sample;

(7) a urine sample.

In addition there is a dental survey and, depending on the population being surveyed, additional measurements may be considered desirable, e.g. visual acuity is being measured in this age-group.

\section{FEASIBILITY STUDY OF THE NATIONAL DIET AND NUTRITION SURVEY OF PEOPLE AGED 65 YEARS OR OVER}

The aim of the feasibility study was to:

(1) develop, assess and refine all the methods, equipment and field-work procedures to be used in the main survey;

(2) establish the likely response rate to all components;

(3) validate the dietary record;

(4) explore the feasibility of collecting a $24 \mathrm{~h}$ urine sample and a venous blood sample after an overnight fast.

The feasibility study was carried out by Social and Community Planning Research with University College London and the Medical Research Council Dunn Nutrition Unit in Cambridge. The main survey will also be carried out by the same contractors. 
The components tested in the feasibility study are described, followed by some outcomes and the changes made to the final survey protocol.

\section{Sampling scheme}

The NDNS programme calls for a randomly-selected nationally-representative sample of between 1600 and 2000 subjects in each survey. The preferred sampling scheme to collect a nationally-representative sample of people aged 65 years or over living in their own homes for the main survey, and which was tested in the feasibility study, was a postal sift based on the small users' file of the Postcode Address File (PAF). Use of both the Department of Social Security Pensions Register and the General Practitioners' (GP) Age-Sex Registers were investigated before the feasibility study but were found to be unsuitable.

In addition the method of sampling individuals living in residential accommodation was tested in the feasibility study. A list of 'homes' had been identified in the report $A n$ Investigation of Sampling Frames of Communal Establishments for the Family Expenditure Survey (Office of Population Censuses and Surveys, 1993). This was identified in the report as List C. For the feasibility study, the residential homes from which the sample of individuals would be picked were selected from the previously mentioned list and five subjects were selected randomly in each home.

Approval to carry out the fieldwork was obtained by the survey doctor from the National Health Service Local Research Ethics Committees (LREC) of the Health Districts in which the subjects were recruited.

\section{Consents}

LREC require subject consent to certain activities or components before these can be included in the survey. It was necessary to test the procedure for obtaining such consents, e.g. to the giving of blood and passing of abnormal blood and blood pressure results to the GP, which were required in order that the nurse could carry out certain tasks. These included: witnessed consent for taking blood sample; consent to send the GP the blood pressure results and certain 'clinically significant' blood analytes results; consent to store blood; consent for subject's name to be passed to the National Health Service Central Register; consent to taking the three tablets of $p$-aminobenzoic acid (PABA) to check the completeness of the $24 \mathrm{~h}$ urine sample (in the feasibility study only). Proxy consent from a close relative or carer had to be obtained for those who were mentally incapacitated and the procedure for this was also tested in the feasibility study.

\section{Interview}

The interview was undertaken to collect the following information: socio-economic and demographic details; usual eating pattern and frequency of consumption of certain foods; factors affecting food consumption, e.g. use of meals on wheels; health; medication and use of dietary supplements; habitual activity and exercise; smoking habits; alcohol consumption; memory test to help identify mental incapacity and the need for proxy information; a state of well-being (or depression) questionnaire (self completed). This format was tested to determine the suitability of the questions for 
collecting the required data and the time taken to administer. The feasibility study also investigated the possibility of taking proxy information for those who were unable to provide information.

\section{Dietary intake record}

Weighed diary records ( $7 \mathrm{~d}$ or $4 \mathrm{~d}$ ) of a $\mathrm{l}$ foods and drinks consumed were tested to determine if elderly people were able to keep detailed records, the suitability of the weighing scales, the response rates, quality of recording and whether there was a fatigue effect after $4 \mathrm{~d}$. In addition the design of the diaries, interviewer coding of the diary records and the calculation of energy and nutrient intakes using a specially-constructed nutrient database were tested.

\section{Bowel-movement record}

A record of the number of daily bowel movements during the dietary recording period was required and was tested for acceptability to the subjects.

\section{Follow-up interview}

A follow-up interview administered by the interviewers to assess the completeness of the dietary record and whether or not it was habitual intake was also tested.

\section{Urine collection}

The feasibility of collecting a $24 \mathrm{~h}$ urine sample with PABA to measure completeness was tested. PABA, a harmless marker which is quantifiably excreted in $24 \mathrm{~h}$ was required to be taken by each subject as three $80 \mathrm{mg}$ tablets with meals in the $24 \mathrm{~h}$ period in which the urine was collected. The volume of the $24 \mathrm{~h}$ urine sample was recorded before analysing for $\mathrm{PABA}$ recovery, $\mathrm{N}$, creatinine, $\mathrm{Na}$ and $\mathrm{K}$.

\section{Anthropometric and physical measurements}

The following anthropometric and physical measurements were carried out by nurses specially trained in the techniques:

Measurement
Height
Arm demi-span
Weight
Triceps and subscapular skinfolds
Mid-upper arm circumference
Waist and hip circumferences
Grip strength

\section{Equipment}

Portable stadiometer

Adapted tape

Soehnle scales

Holtain skinfold calipers

Insertion tape

Insertion tape

Nottingham Handgrip Dynamometer

Particular attention was paid to the suitability of the equipment and to any problems of intra- and inter-variability of measurements in the nurses. An evaluation of the intra- and inter-variability led to the conclusion that skinfold measurements were not acceptable 
when using a large number of fieldworkers. Skinfold measurements are not being made in the main survey.

In addition the measurement of diastolic, systolic and mean blood pressure using the Dinamap 2000, as used in the Department of Health's Health Survey, and the collection of a fasting blood sample (approximately $30 \mathrm{ml}$ ) using a vacuum-container system for collection were tested. Other components tested included: procedures for recruitment of field laboratories, storage, and transportation of blood and urine samples in the field; processing and analyses of blood and urine samples; reporting of abnormal results to subjects and GP; visual acuity test (an add-on research project). Also, the dental survey was piloted after the feasibility study of the diet and nutritional status components.

\section{METHODS}

The fieldwork was divided into interviewer and nurse tasks. Trained interviewers were responsible for introducing the survey to the subjects, carrying out the interviews, overseeing the dietary records and coding the diaries, administering the bowelmovement record and for introducing the nurse to the subjects. Nurses trained in phlebotomy of this age-group were responsible for obtaining written consent to collecting a blood sample and for taking PABA during the $24 \mathrm{~h}$ urine collection. In addition they carried out the anthropometry, measured blood pressure and grip strength, collected the blood and urine samples and despatched these to the laboratories and carried out the visual acuity test.

\section{Sample}

For the feasibility study free-living subjects were recruited in ten Health Districts, representing different regions of the mainland of England, Wales and Scotland, using the PAF sampling scheme. In addition ten institutions were selected from the Office of Population Censuses and Surveys (1993) List C of Communal Establishments. A sample of approximately 250 subjects was required for the feasibility study.

Following the PAF screen for free-living subjects in this age-group, a sample of individuals (one per address) was selected. A letter was sent to each subject explaining that they had been selected for the feasibility study and giving a brief outline of the purpose of the survey in advance of the interviewer calling. At the first visit each potential subject was given a full explanation of the components of the survey, including the voluntary nature of participation. Consent to participate was sought for each component so that subjects could choose to take part in some aspects of the survey and not others. Explicit formal consent was sought for some components, e.g. PABA-dosing, and in the case of subjects who are mentally incapacitated proxy consent was required from a close relative or carer who is normally responsible for the welfare of the subject.

\section{Interview}

Each subject was asked to participate in an interviewer-administered questionnaire. Where subjects were suspected as being mentally incapacitated, the interviewer administered the short memory questionnaire at an early stage in order to determine the need for proxy information. Otherwise this test was generally left until later in the protocol. 
The main questionnaire was intended to be completed at the first visit which was then followed by an introduction to and demonstration of the dietary record.

\section{Dietary record}

Subjects were divided randomly and asked to keep a $4 \mathrm{~d}$ or a $7 \mathrm{~d}$ weighed dietary record. They were each provided with a set of Soehnle Quanta digital scales and two recording diaries; the 'home record' diary for use when it was possible for foods to be weighed, generally foods eaten in the home, and a smaller 'eating out' diary for use when foods could not be weighed, generally foods and drinks eaten outside the home. The recording method was demonstrated by trained interviewers to subjects or their carers on the day before the start of the record and the interviewer returned within $24 \mathrm{~h}$ to check on the completeness of the record and to provide encouragement. Three to five visits were made to each subject during the food recording period depending on its length and the support required by the subject. An incentive payment of $£ 10$ was offered to each subject for completion of the dietary record.

\section{Diary coding}

The dietary records were coded by interviewers using a coding frame designed by nutritionists at MAFF. New codes were added for foods or recipes recorded for which no code existed and missing weights were added by the survey nutritionist. The total daily weight of each coded food or drink item was calculated for each subject and from this the daily energy and nutrient intakes were calculated using a nutrient database provided by MAFF.

\section{Blood pressure}

Blood pressure was measured with the Dinamap 2000. Nurses were instructed to report certain high and low blood pressure measurements immediately to the subject's GP and the survey doctor by telephone at the time of examination. These were: (a) systolic blood pressure of $180 \mathrm{mmHg}$ or above and/or (b) diastolic blood pressure of $120 \mathrm{mmHg}$ or above, (c) systolic blood pressure of $90 \mathrm{mmHg}$ or below. Mean arterial blood pressure was ignored.

\section{Blood sample}

Overnight fasting venous blood samples (about $28 \mathrm{ml}$ ) were collected from all those respondents who were willing to be bled. Blood was collected in a $30 \mathrm{ml}$ syringe (later, separate Sarstedt monovettes were substituted, to reduce the risk of clotting). No more than two attempts were made to obtain blood. Normally the antecubital vein was used, but failing that an alternative forearm vein was used. The procedures for taking the blood, recruitment of field laboratories, storage, and transportation in the field, processing and analyses were all tested.

The blood sample was subdivided into EDTA $(2.8 \mathrm{ml})$, citrate $(1.4 \mathrm{ml})$, heparin $(20$ $\mathrm{ml})$ anticoagulants and clotted blood for serum $(4.8 \mathrm{ml})$. Three tubes from each sample were posted (first class) to Addenbrooke's Haematology Laboratory, for full blood 
counts and differentials; fibrinogen, prothrombin time and activated partial thromboplastin time, and for serum ferritin, folate and vitamin $\mathrm{B}_{12}$. Remaining heparinized blood was transported immediately after collection, in a cool-box, to a local hospital laboratory for separation and preliminary processing. Portions of whole blood or washed erythrocytes were stored for erythrocyte folate, glutathione peroxidase (EC 1.11.1.9; Se status), glutathione reductase ( $E C$ 1.6.4.2; riboflavin status) and transketolase ( $E C$ 2.2.1.1; thiamin status) assays. A portion of plasma was stabilized with metaphosphoric acid for vitamin $C$ determination. Plasma levels of fat-soluble vitamins $(A, D, E$ and carotenoids); minerals ( $\mathrm{Zn}, \mathrm{Cu}, \mathrm{Fe}$, total Fe-binding capacity (TIBC), Ca, phosphate); lipids (cholesterol, HDL-cholesterol, triacylglycerols); proteins (albumin, $\alpha$-1-antichymotrypsin, alkaline phosphatase $(E C$ 3.1.3.1), $\gamma$-glutamyltransferase $(E C$ 2.3.2.2) ) and renal function tests (urea and creatinine), were measured later at the Dunn Nutrition Unit, Cambridge.

Certain analytes were considered to be clinically significant. These were haemoglobin, total and differential leucocyte count, platelets, clotting times, fibrinogen, ferritin, vitamin $\mathrm{B}_{12}$, folate, cholesterol, creatinine, Fe, TIBC, Fe saturation, urea, albumin and vitamin $\mathrm{D}$. Normal limits for these analytes were set based on values used by the Clinical Haematology Laboratory at Addenbrooke's Hospital and literature values. Values falling outside these limits were reported to the subject's GP, provided consent had been obtained to do this. The most common apparent clinically significant abnormalities were low $\mathrm{Fe}(22 \%)$, albumin $(12 \%)$, high or low haemoglobins $(12 \%)$ and prolonged clotting times $(11 \%)$. In addition, a fibrinogen level above the arbitrary normal range was found in $24 \%$ of all subjects. There was concern at the high frequency of apparent abnormalities identified in the feasibility study and consequently a review of the criteria for the main survey has been undertaken and some changes made, as set out in Table 1.

\section{OUTCOMES AND IMPLICATIONS FOR THE MAIN SURVEY}

\section{Response rates}

Responses to the various components of the survey are set out in Table 2. Response to some components was better in the free-living subjects than in the institutionalized subjects and a need was identified for improved response rates in the main survey, especially to the dietary record and nurse components. Interviewers considered that the main reason for low response to many of the components was the overall burden of the survey. This has been addressed and whilst most components have been retained for the main survey they have been packaged to make them less burdensome.

A sample of 143 free-living subjects (age range 65-91 years) provided a main interview (the first component of the survey) and of these ninety-four $(66 \%)$ agreed to keep a weighed dietary record, and seventy-one $(50 \%)$ provided a blood sample (Table 2 ).

More free-living subjects agreed to keep a $4 \mathrm{~d}$ record (4DR) than a $7 \mathrm{~d}$ record (7DR) (fifty-three kept a 4DR and forty-one kept a 7DR) and the completion rate to the 4DR (fifty-one of fifty-three) was better than that for the 7DR (thirty-seven of forty-one). The response to the dietary record was lower for females than for males and response rate dropped dramatically amongst those aged 85 years or over. The proportion of the institution sample completing food records was only $40 \%$ (see Table 3 ).

A comparison of the group mean daily intakes of energy and selected nutrients for both $4 \mathrm{DR}$ and 7DR is set out in Table 4. ANOVA showed that there were no significant 
Table 1. Feedback of clinically significant abnormalities of blood analytes from a sample of subjects aged 65 years or over*

\begin{tabular}{lcc}
\hline \hline & $\begin{array}{c}\text { Feasibility study } \\
\text { reference normal range }\end{array}$ & $\begin{array}{c}\text { Main survey } \\
\text { reference normal range }\end{array}$ \\
\hline Blood count & $120-150$ & $100-180$ \\
Haemoglobin $(\mathrm{g} /)$ & $76-100$ & $76-100$ \\
Mean cell volume $(\mathrm{fl})$ & $27-32$ & $27-32$ \\
Mean cell haemoglobin $(\mathrm{pg})$ & $150-450$ & $100-450$ \\
Platelets $\left(10^{9} / \mathrm{l}\right)$ & $4-11$ & $4-15$ \\
Leucocyte count $\left(10^{9} / \mathrm{l}\right)$ & $2-7 \cdot 5$ & $2-7 \cdot 5$ \\
Neutrophils $\left(10^{9} /\right)$ & $\leq 0 \cdot 1$ & $\leq 0 \cdot 1$ \\
Basophils $\left(10^{9} / 1\right)$ & $1 \cdot 5-4$ & $1 \cdot 5-4$ \\
Lymphocytes $\left(10^{9} /\right)$ & $0 \cdot 2-0 \cdot 8$ & $0 \cdot 2-0 \cdot 8$ \\
Monocytes $\left(10^{9} /\right)$ & $0 \cdot 04-0 \cdot 4$ & $0 \cdot 04-0 \cdot 4$ \\
Eosinophils $\left(10^{9} /\right)$ & & \\
Clotting screen & $12-16$ & $12-17$ \\
Prothrombin time $(\mathrm{s})$ & $30-41$ & $28-42$ \\
Activated thromboplastin time $(\mathrm{s})$ & $1 \cdot 5-4$ & $1 \cdot 5-8$ \\
Fibrinogen $(\mathrm{g} / \mathrm{l})$ & $3-18$ & $>3$ \\
Serum folate $(\mu \mathrm{g} / \mathrm{l})$ & $150-900$ & $>150$ \\
Serum vitamin $\mathrm{B} / 2(\mathrm{ng} / \mathrm{l})$ & $15-235$ & $10-300$ \\
Serum ferritin $(\mu \mathrm{g} / \mathrm{l})$ & $>15$ & $>15$ \\
Percentage Fe saturation & $>9$ & $>9$ \\
Plasma Fe $(\mu \mathrm{M})$ & $<73$ & $<73$ \\
TIBC $(\mu \mathrm{M})$ & $<7 \cdot 8$ & $<8$ \\
Plasma cholesterol $(\mathrm{mM})$ & $>30$ & $>30$ \\
Plasma albumin $(\mathrm{g} / \mathrm{l})$ & $<150$ & $<150$ \\
Plasma creatinine $(\mu \mathrm{M})$ & $<12$ & $<12$ \\
Plasma urea $(\mathrm{mM})$ & $>12 \cdot 5$ & $>12 \cdot 5$ \\
Plasma 25 -hydroxycholecalciferol $(\mathrm{nM})$ & & $<-5$ \\
\hline \hline
\end{tabular}

TIBC, total Fe-binding capacity.

* For details, see page 637.

Table 2. Feasibility study: response to recruitment for various components in a sample of subjects aged 65 years or over*

\begin{tabular}{|c|c|c|c|c|c|c|}
\hline & \multicolumn{3}{|c|}{ Free-living subjects } & \multicolumn{3}{|c|}{ Subjects living in institutions } \\
\hline & $n$ & $\% \dagger$ & $\% \ddagger$ & $n$ & $\% \dagger$ & $\% \ddagger$ \\
\hline Eligible sample after sift & 200 & 100 & & 45 & 100 & \\
\hline Productive main interview & 143 & 72 & 100 & 35 & 78 & 100 \\
\hline Whole or part food diary & 94 & 47 & 66 & 19 & 42 & 54 \\
\hline Agreed to nurse visit & 97 & 49 & 68 & 20 & 44 & 57 \\
\hline Nurse schedule completed & 86 & 43 & 60 & 19 & 42 & 54 \\
\hline Blood samples obtained & 71 & 36 & 50 & 10 & 22 & 34 \\
\hline $24 \mathrm{~h}$ urine sample obtained & 73 & 37 & 51 & 12 & 27 & 34 \\
\hline
\end{tabular}

* For details of subjects and procedures, see p. 633.

$\dagger$ Percentage of eligible sample.

$\ddagger$ Percentage of those providing a productive main interview. 
Table 3. Feasibility study: response of free-living subjects aged 65 years or over to $4 d$ $(4 D R)$ and $7 d$ dietary records $(7 D R)^{*}$

\begin{tabular}{|c|c|c|c|c|c|c|}
\hline & \multicolumn{3}{|c|}{ 4DR } & \multicolumn{3}{|c|}{ 7DR } \\
\hline & $n$ & $\% \dagger$ & $\% \ddagger$ & $n$ & $\% \dagger$ & $\% \neq$ \\
\hline Eligible sample & 100 & 100 & & 100 & 100 & \\
\hline Productive main interview & 74 & 75 & & 69 & 69 & \\
\hline Agreed to keep a dietary record & 53 & 53 & 72 & 41 & 41 & 59 \\
\hline Completion of dietary record & 51 & 51 & 69 & 37 & 37 & 54 \\
\hline
\end{tabular}

* For details of subjects and procedures, see pp. 633-634.

$\dagger$ Percentage of total eligible sample.

$\$$ Percentage of those providing a productive main interview.

Table 4. Feasibility study: differences in group mean daily intakes of a sample of subjects aged 65 years or over between $4 d$ records $(4 D R)$ and $7 d$ records $(7 D R)^{*}$

\begin{tabular}{|c|c|c|c|c|c|c|}
\hline \multirow[b]{2}{*}{ Nutrient } & \multicolumn{2}{|c|}{ Males } & \multicolumn{2}{|c|}{ Females } & \multirow[b]{2}{*}{$F$ value $\uparrow$} & \multirow{2}{*}{$\begin{array}{c}\text { Statistical } \\
\text { significance } \\
\text { of difference } \\
\text { between } \\
\text { 4DR and 7DR: } \\
P=\end{array}$} \\
\hline & $\begin{array}{c}\text { 4DR } \\
29\end{array}$ & $\begin{array}{c}7 \mathrm{DR} \\
23\end{array}$ & $\begin{array}{c}4 \mathrm{DR} \\
24\end{array}$ & $\begin{array}{c}7 \mathrm{DR} \\
22\end{array}$ & & \\
\hline Energy (kJ) & 8169 & 8152 & 5821 & 5935 & 0.02 & 0.90 \\
\hline Fat $(\mathrm{g})$ & $74 \cdot 0$ & $77 \cdot 6$ & $60 \cdot 0$ & $58 \cdot 1$ & 0.05 & 0.83 \\
\hline Protein (g) & $73 \cdot 3$ & $70 \cdot 6$ & $55 \cdot 9$ & $55 \cdot 6$ & $0 \cdot 24$ & $0 \cdot 62$ \\
\hline Starch $(g)$ & $137 \cdot 9$ & $137 \cdot 0$ & $91 \cdot 7$ & $97 \cdot 2$ & $0 \cdot 10$ & 0.75 \\
\hline NMES (g) & $66 \cdot 0$ & $65 \cdot 7$ & $39 \cdot 8$ & $41 \cdot 5$ & . $0 \cdot 01$ & 0.91 \\
\hline $\mathrm{NSP}(\mathrm{g})$ & $14 \cdot 6$ & $14 \cdot 2$ & $9 \cdot 8$ & $11 \cdot 6$ & 0.47 & 0.50 \\
\hline $\mathrm{Ca}(\mathrm{mg})$ & 924 & 806 & 680 & 703 & 0.67 & 0.42 \\
\hline $\mathrm{Fe}(\mathrm{mg})$ & $12 \cdot 4$ & $11 \cdot 1$ & $9 \cdot 1$ & $10 \cdot 1$ & 0.06 & 0.81 \\
\hline$\beta$-Carotene $(\mu \mathrm{g})$ & 1694 & 1711 & 1554 & 1851 & 0.51 & 0.49 \\
\hline
\end{tabular}

NMES, non-milk extrinsic sugars.

* For details of subjects and procedures, see pp. 633-634.

$\dagger$ Applies to difference between 4DR and 7DR after eliminating sex difference.

differences between the 4DR and 7DR for energy intake and the selected nutrients tested. As a result a 4DR was selected for the main survey to maximize the response rate. This will be collected over four consecutive days because the interviewers advised that subjects would be reluctant to restart the record once stopped.

Differences between the group muan intake for each day of the week were tested using ANOVA after removing the effect of differences between individuals. The results are set out in Table 5. There were few statistically significant differences. However, the mean daily intake of $\beta$-carotene was significantly higher on Sundays than on other days of the week. Differences between days of the week will be further investigated in the main survey and any decision to weight the data to account for any such differences found then will be taken at the time. It was considered essential to have records for all days of the week in the main survey for the whole population because of the significant differences in 
Table 5. Feasibility study: group mean daily intake of energy and nutrients on different days of the week for a sample of subjects aged 65 years or over*

\begin{tabular}{|c|c|c|c|c|c|c|c|c|c|}
\hline & \multicolumn{7}{|c|}{ Group mean daily intakes } & \multirow{2}{*}{$\begin{array}{c}F \\
\text { value } \dagger\end{array}$} & \multirow{2}{*}{$\begin{array}{c}\text { Statistical } \\
\text { significance } \\
\text { of difference } \\
\text { between } \\
\text { days of the } \\
\text { week: } P=\end{array}$} \\
\hline & Mon & Tues & Wed & Thur & Fri & Sat & Sun & & \\
\hline Energy: MJ & $6 \cdot 8$ & $7 \cdot 0$ & $6 \cdot 7$ & $7 \cdot 1$ & $7 \cdot 4$ & $7 \cdot 2$ & $7 \cdot 1$ & 0.78 & $0 \cdot 58$ \\
\hline kcal & 1630 & 1666 & 1612 & 1692 & 1772 & 1724 & 1695 & & \\
\hline Fat $(\mathrm{g})$ & $65 \cdot 3$ & $66 \cdot 1$ & $62 \cdot 6$ & $66 \cdot 9$ & $75 \cdot 4$ & $68 \cdot 5$ & $69 \cdot 6$ & $1 \cdot 26$ & $0 \cdot 27$ \\
\hline Protein $(\mathrm{g})$ & $62 \cdot 1$ & $66 \cdot 8$ & $62 \cdot 6$ & $65 \cdot 1$ & $64 \cdot 3$ & $62 \cdot 4$ & $65 \cdot 7$ & $1 \cdot 03$ & 0.41 \\
\hline Starch (g) & $114 \cdot 9$ & $117 \cdot 5$ & 111.5 & $120 \cdot 3$ & $123 \cdot 3$ & $117 \cdot 0$ & $115 \cdot 7$ & $1 \cdot 31$ & 0.25 \\
\hline NMES (g) & $51 \cdot 8$ & $52 \cdot 8$ & 52.9 & $54 \cdot 5$ & $52 \cdot 1$ & $57 \cdot 2$ & $56 \cdot 6$ & 0.78 & 0.59 \\
\hline NSP (g) & $12 \cdot 5$ & $12 \cdot 8$ & $12 \cdot 3$ & $13 \cdot 1$ & $13 \cdot 0$ & $12 \cdot 2$ & $13 \cdot 1$ & $0 \cdot 46$ & 0.84 \\
\hline $\mathrm{Ca}(\mathrm{mg})$ & 758 & 877 & 769 & 773 & 800 & 730 & 742 & $2 \cdot 05$ & 0.06 \\
\hline $\mathrm{Fe}(\mathrm{mg})$ & $10 \cdot 1$ & $11 \cdot 2$ & $10 \cdot 7$ & $10 \cdot 9$ & $10 \cdot 6$ & $11 \cdot 3$ & $10 \cdot 2$ & $1 \cdot 02$ & 0.41 \\
\hline$\beta$-Carotene $(\mu \mathrm{g})$ & 1690 & 1810 & 1588 & 1707 & 1339 & 1430 & 2637 & 4.43 & 0.00 \\
\hline
\end{tabular}

NMES, non-milk extrinsic sugars.

* For details of subjects and procedures, see pp. 633-634.

$\dagger$ Applies to difference between days of the week after eliminating for individual differences.

the intake of some nutrients between different days of the week. A diary placement pattern has been selected which will ensure that there is an even spread of diary start days throughout the week.

\section{Validation of dietary record}

Completed dietary records and urine data were available for sixty-nine subjects (thirty-seven 4DR and thirty-two 7DR). Results for the group mean $24 \mathrm{~h}$ urine $\mathrm{N}$ and $\mathrm{K}$ and the group mean daily dietary $\mathrm{N}$ and $\mathrm{K}$ are presented in Table 6 for males and females for all sixty-nine subjects. Table 7 presents the data for those subjects whose PABA recovery was greater than $60 \%$ (indicative that they had taken all three tablets) and less than $110 \%$. The values for urine $\mathrm{N}$ :dietary $\mathrm{N}$ and of urine $\mathrm{K}$ :dietary $\mathrm{K}$ were changed little when only those subjects with a near-complete PABA recovery were included in the analyses. The correlation coefficient increased for all subjects from 0.52 to 0.63 for $\mathrm{N}$ and from 0.62 to 0.69 for $\mathrm{K}$. An investigation of this and other studies of PABA recovery with the other urine constituents measured demonstrated a straight-line relationship between PABA and the other urine constituents above $70 \%$ PABA recovery. When results for urine $\mathrm{N}$ and dietary $\mathrm{N}$ were corrected to $93 \%$ PABA recovery (that expected if all collections were complete) the values for urine $\mathrm{N}$ :dietary $\mathrm{N}$ increased to 0.92 for men and 0.87 for women which is close to the expected range of $0.70-0.90$ for validity (Bingham \& Cummings, 1985).

For the small number of subjects for which both dietary and urine data were available, therefore, it appeared that the 4DR method tested in the feasibility study, with some minor modifications, would provide valid intake data for the free-living sample. Because a substantial number of non-responders cited the task of weighing each item of food and 
Table 6. Feasibility study: comparison of urine and dietary nitrogen and potassium in all subjects aged 65 years or over for whom both records were available*

(Mean values and standard deviations)

\begin{tabular}{|c|c|c|c|c|}
\hline & \multicolumn{2}{|c|}{ Males ( $n$ 36) } & \multicolumn{2}{|c|}{ Females ( $n$ 33) } \\
\hline & Mean & $\mathrm{SD}$ & Mean & SD \\
\hline Age (years) & 74.9 & $6 \cdot 3$ & $75 \cdot 4$ & $7 \cdot 1$ \\
\hline PABA recovery $(\%)$ & $75 \cdot 8$ & $41 \cdot 0$ & $65 \cdot 7$ & $35 \cdot 6$ \\
\hline Mean daily energy: kcal & 1938 & 407 & 1484 & 457 \\
\hline $\mathrm{MJ}$ & $8 \cdot 1$ & & $6 \cdot 2$ & \\
\hline $24 \mathrm{~h}$ urine $\mathrm{N}(\mathrm{g})$ & $10 \cdot 0$ & $4 \cdot 8$ & $7 \cdot 2$ & $2 \cdot 8$ \\
\hline Mean daily intake of dietary $\mathrm{N}(\mathrm{g})$ & $11 \cdot 6$ & $2 \cdot 8$ & $9 \cdot 3$ & $2 \cdot 5$ \\
\hline Urine N:dietary $N$ & 0.86 & 0.40 & $0 \cdot 80$ & $0 \cdot 34$ \\
\hline 24 h urine $\mathrm{K}$ (mmol) & 59.4 & $28 \cdot 5$ & $46 \cdot 7$ & $20 \cdot 0$ \\
\hline Mean daily intake of dietary $\mathrm{K}$ ( $\mathrm{mmol}$ ) & $69 \cdot 7$ & $17 \cdot 7$ & $57 \cdot 1$ & $18 \cdot 8$ \\
\hline Urine $\mathrm{K}$ :dietary $\mathrm{K}$ & 0.85 & $0-34$ & 0.83 & 0.31 \\
\hline
\end{tabular}

Pearson correlation coefficient for dietary and urine $\mathrm{N}$ for males and females $(n 69)$ was 0.52 and for dietary and urine $\mathrm{K}$ was 0.62 .

PABA, $p$-aminobenzoic acid.

* For details of subjects and procedures, see pp. 633-634.

Table 7. Feasibility study: comparison of urine and dietary nitrogen and potassium in all subjects aged 65 years or over for whom a near complete collection of $\mathrm{p}$-aminobenzoic acid (PABA) was obtained*

(Mean values and standard deviations)

\begin{tabular}{|c|c|c|c|c|}
\hline & \multicolumn{2}{|c|}{ Males ( $n$ 25) } & \multicolumn{2}{|c|}{ Females ( $n$ 18) } \\
\hline & Mean & SD & Mean & SD \\
\hline Age (years) & $73 \cdot 6$ & $6 \cdot 1$ & $74 \cdot 4$ & $5 \cdot 7$ \\
\hline PABA recovery $(\%)$ & $89 \cdot 0$ & $10 \cdot 4$ & $78 \cdot 5$ & $8 \cdot 4$ \\
\hline Mean daily energy: kcal & 1970 & 379 & 1554 & 524 \\
\hline $\mathrm{MJ}$ & $8 \cdot 3$ & & $6 \cdot 5$ & \\
\hline $24 \mathrm{~h}$ urine $\mathrm{N}(\mathrm{g})$ & $10 \cdot 4$ & $3 \cdot 1$ & $7 \cdot 9$ & $2 \cdot 1$ \\
\hline Mean daily intake of dietary $N(g)$ & $12 \cdot 0$ & $3 \cdot 1$ & 9.7 & $2 \cdot 5$ \\
\hline Urine $\mathrm{N}$ :dietary $\mathrm{N}$ & 0.89 & $0 \cdot 28$ & $0 \cdot 86$ & 0.26 \\
\hline $24 \mathrm{~h}$ urine $\mathrm{K}(\mathrm{mmol})$ & $61 \cdot 4$ & $21 \cdot 1$ & $51 \cdot 5$ & $15 \cdot 8$ \\
\hline Mean daily intake of dietary $\mathrm{K}(\mathrm{mmol})$ & $71 \cdot 6$ & $17 \cdot 3$ & $61 \cdot 6$ & $21 \cdot 7$ \\
\hline Urine $\mathrm{K}$ :dietary $\mathrm{K}$ & $0 \cdot 86$ & $0 \cdot 21$ & 0.89 & $0 \cdot 27$ \\
\hline
\end{tabular}

Pearson correlation coefficient for dietary and urine $\mathrm{N}$ for males and females $(n 43)$ was 0.61 and for dietary and urine $\mathrm{K}$ was $0 \cdot 70$.

* For details of subjects and procedures, see pp. 633-634.

drink as the reason for non-participation, it was decided that for the main survey the interviewers could use their discretion and offer a semi-quantitative diary to such subjects. In such cases the interviewers are instructed to obtain as many weights as possible by calling at meal times. 
The response rate to the dietary record in the institutional sample was very poor and the quality of those diaries obtained was also poor. A decision to greatly modify the collection of dietary data from these subjects was reached and has been tested in a pilot study. The onus to collect the data was switched from the subjects and their carers to the interviewer. The interviewer has to weigh a main meal every day during the $4 \mathrm{~d}$ recording period and the institution staff and/or subjects record details of the types and amounts (not weighed) of foods and drinks consumed by the subject on a food record. The interviewer transfers the information from the food record and eating out diary into the main food and drink diary along with estimated portion sizes collected on the food providers' (cooks') questionnaire designed to elicit additional information about the types and quantities of foods served.

\section{Urine collection}

Some difficulties were encountered in the collection of $24 \mathrm{~h}$ urine samples. The procedure proved to be difficult for many subjects and unsuccessful in a substantial number of cases. It has been decided to replace the $24 \mathrm{~h}$ urine collection by the simpler collection of an overnight 'spot' urine sample in the main survey which will be analysed for $\mathrm{Na}, \mathrm{K}$ and creatinine.

\section{CONCLUSION}

The feasibility study led to several significant changes to the protocol for the main survey, including:

(1) dividing the initial questionnaire into three sections, which could be administered on separate occasions, to avoid subject fatigue leading to reduced response;

(2) collecting a 4DR (rather than 7DR);

(3) allowing the use of semi-quantitative dietary records where the requirement for a weighed record was considered likely to lead to non-participation;

(4) reducing the number of subjects in each residential home from five to three;

(5) a new method of collecting the dietary record from institutionalized subjects;

(6) the omission of the triceps and subscapular skinfold measurements;

(7) the omission of the $24 \mathrm{~h}$ urine collection, in favour of spot urine sample;

(8) use of Sarstedt monovettes for blood collection to reduce clotting in the tubes;

(9) improved training of both interviewers and nurses.

The feasibility study was generally felt to be an extremely necessary, instructive and constructive element of the survey, which has served to eliminate many serious problems, and has provided a more solid base on which to proceed with the main survey.

It is hoped that the report of the main survey will be published during 1997 after which the data will be archived for the use of those who wish to investigate it further.

\section{REFERENCES}

Bingham, S. \& Cummings, J. (1985). Urine nitrogen as an independent validatory measure of dietary intake. American Journal of Clinical Nutrition 42, 1276-1289.

Department of Health (1989). The Diets of British Schoolchildren. Report on Health and Social Subjects no. 36. London: H.M. Stationery Office. 
Department of Health (1992). The Nutrition of Elderly People. Report on Health and Social Subjects no. 43. London; H.M. Stationery Office.

Department of Health and Social Security (1979). Nutrition and Health in Old Age. Report on Health and Social Subjects no. 16. London: H.M. Stationery Office.

Gregory, J., Foster, K., Tyler, H. \& Wiseman, M. (1990). The Dietary and Nutritional Survey of British Adults. London: H.M. Stationery Office.

Gregory, I. R., Collins, D. L., Davies, P. S. W., Hughes, J. M. \& Clarke, P. C. (1995). The National Diet and Nutrition Survey of Children Aged 11/2 to 4l/2 Years. Vol. 1, Diet and Nutrition Survey. London: H.M. Stationery Office.

Office of Population Censuses and Surveys (1993). An Investigation of Sampling Frames of Communal Establishments for the Family Expenditure Survey. London: H.M. Stationery Office. 